\title{
Factors Associated with the Use of Cervical Cancer Screening in the Mbour Health District (Senegal)
}

\author{
Niang Khadim 1,2, Tine Jean Augustin Diegane ${ }^{2}$, Thiam Ousmane'1, Ly Toly ${ }^{3}$, \\ Diongue Fatoumata Bintou ${ }^{2}$, Diallo Amadou Ibra ${ }^{2}$, Faye Adama ${ }^{2}$, Ndiaye Papa ${ }^{1}$ \\ ${ }^{1}$ Public Health Department, Gaston Berger University (UGB), Saint-Louis, Senegal \\ ${ }^{2}$ Institut de Santé et Développement, Cheikh Anta Diop University, Dakar, Senegal \\ ${ }^{3}$ Mbour Department Hospital, Thies, Senegal \\ Email: khadimniang@outlook.com
}

How to cite this paper: Khadim, N., Diegane, T.J.A., Ousmane, T., Toly, L., Bintou, D.F., Ibra, D.A., Adama, F. and Papa, N. (2020) Factors Associated with the Use of Cervical Cancer Screening in the Mbour Health District (Senegal). Open Journal of Obstetrics and Gynecology, 10, 604-614. https://doi.org/10.4236/ojog.2020.1040054

Received: January 2, 2020

Accepted: April 23, 2020

Published: April 26, 2020

Copyright $\odot 2020$ by author(s) and Scientific Research Publishing Inc. This work is licensed under the Creative Commons Attribution International License (CC BY 4.0).

http://creativecommons.org/licenses/by/4.0/

\begin{abstract}
Cervical cancer with an estimated incidence between 1700 and 2000 new cases per year and mortality around $70 \%$ to $80 \%$ has become the leading cancer in Senegal. The objectives of this present work were to study the factors associated with cervical cancer screening in the Mbour health district in 2015. It was a cross-sectional, descriptive and analytical study carried out on a sample of 599 women chosen according to a two-stage survey. The survey used a questionnaire where data on individual characteristics, knowledge, attitudes and practices are collected during an individual interview after informed consent. The data collected were entered in the Epi Info 3.5.3 software and analyzed with the R 3.1.2 software. The average age was 44.4 years with a standard deviation of 8.9. The proportion of women screened for cervical cancer was $19.4 \%$. Screening for cervical cancer was positively related to the possession of an income-generating activity (Adjusted OR $=2.39[1.4-4.2]$ ), increase of education and knowledge of a person suffering from cancer in the environment (adjusted OR $=2.40[1.3-4.2]$ ). Knowledge of the methods of diagnosis of cervical cancer was positively associated with cervical cancer screening (adjusted OR $=20$ [11.1 - 33.3]). The lack of awareness and the lack of financial resources and education for women were the main obstacles to cervical cancer screening for women in Mbour. The health system should focus on building the capacity of women to fight cervical cancer.
\end{abstract}

\section{Keywords}

Cancer, Cervix, Screening, Women, Senegal 


\section{Introduction}

Cervical cancer (CCU) is linked to persistent infection with certain human papillomaviruses (HPV) [1]. It is a real public health problem. With a devastating impact on women's health, especially in developing countries, cervical cancer worldwide accounts for $10 \%$ of female cancers and ranks second behind women's breast cancer.

According to the World Health Organization [2] 18 million new cases were diagnosed in 2018 with 8.5 million cancer-related deaths. This scourge represents one of the most serious damage to health of women in countries with limited resources. According to the WHO if no preventive action including "organized screening of women who are sexually active or who have been" is planned, the deaths from this type of gynecological and breast cancer will increase by $25 \%$ over the ten next years in these same countries [2]. However, industrialized countries where screening for UCC are organized; there has been a steady decline in the incidence and mortality of this cancer for over 50 years and this pathology is becoming increasingly rare [3]. In developing countries, cytological screening programs for cervical cancer have been introduced over the past 30 years. Thus, in South Africa [4], the IVA, coupled with the immediate treatment of positive women from the first visit, allowed the reduction of the incidence of cancer by $26 \%$ and was economical in terms of cost/efficiency.

According to the WHO [5] in 2010, in Senegal there were 1197 cases of CCU declared and 795 died, i.e. a fatality rate of $66.41 \%$. Efforts have been made in recent years to improve the management of cervical cancer with the availability of visual inspection tests in public structures, the training of health personnel, the introduction of HPV vaccination in girls but also the realization of mass campaigns of screening for gynecological cancers.

However, the use of screening remains low, estimated at $12 \%$ at the national level in 2015 [6]. This work thus makes it possible to study the associated factors of cervical cancer screening of women aged 35 to 65 years from the Mbour health district.

\section{Methodology}

\subsection{Study Framework}

Mbour is one of the departments of the Thies region. The Thies region represents one of the 14 regions of Senegal, and is located $70 \mathrm{~km}$ from the capital, Dakar.

The health district of Mbour has an area of $526 \mathrm{~km}^{2}$ and occupies the northwest part of the department of the same name.

The population in 2014 was estimated at 354,141 inhabitants. There is a high population density with 658 inhabitants $/ \mathrm{km}^{2}$. The annual growth rate is 2.7 inhabitants, and the population is very young with $57 \%$ aged under 20 years. The district of Mbour is an area of high migration due to the rapid development of economic activities such as fishing and tourism.

The operational area of Mbour represents the first district of the department 
in terms of socio-health infrastructures, with 24 health posts and 1 health center, 18 maternity wards and 20 health outposts. There are many private health structures which do not respect the traditional organization of the health system; the health information of these structures is not always capitalized in the reports of the health district.

The management of cervical cancer occupies an important place in the health district of Mbour. In 2015, a major program was implemented consisting of screening by visual inspection with acetic acid and Lugol at all service points and positive cases referred to the health center or the hospital for a colposcopy and possibly a biopsy.

\subsection{Study Type}

The study was cross-sectional, descriptive and analytical and took place during the last quarter of 2015.

\subsection{Study Population and Sampling Protocol}

The survey population was represented by all women aged $35-65$ from the Mbour health district.

To be included in this study, the woman had to reside in the area of responsibility of the Mbour health district for at least 6 months. Women who were absent, those who were not available during the collection phase and those who refused to participate were not included

The sample size was calculated by the Schwartz formula $(n=(\varepsilon 2 \times p \times q) / i 2)$.

With prevalence of breast cancer screening in women of reproductive age the p was not known, we chose $50 \%, \varepsilon=1.96$ and an accuracy of 5\%, the number is equal to 384 individuals. To minimize the cluster effect, we multiplied the result obtained by 1.5, giving a population of 576 .

A two-stage cluster survey was conducted. The first step was to draw villages or neighborhoods to investigate. The second degree concerned the drawing of the concessions. Depending on the size of the population of the selected district or village, groups of concessions are formed. In each concession, the investigator interviewed all women who met the inclusion criteria. The selection of the following concessions was made with leaps of three.

\subsection{Collection of Data}

For the study, a questionnaire was used to collect data from the women to be surveyed. This questionnaire was drawn up using a systematic document review and built around the dimensions of Andersen's conceptual framework [7] on accessibility to care services. So it had the following dimensions:

- Individual characteristics: age, income-generating activity, marital status, education, etc.

- Knowledge (resources): diagnostic methods, places of screening, possibility of recovery, cancer cases in the surroundings, information on cancer...

- Needs: types of exams to help the patient. 
To study knowledge, coding was done to identify women with good knowledge (Table 1).

Twelve investigators trained in data collection were responsible for conducting the investigation. The questionnaires were administered by direct interview in the women's own homes.

\subsection{Data Entry and Analysis}

The data was entered on the Epi Info 7.2 software.

The data was analyzed with the R 3.3.1 software [8]. Qualitative variables were described with absolute and relative frequencies and quantitative variables by mean and standard deviation.

Multivariate analysis was performed with a simple logistic regression for determination factors related to breast cancer screening, with adjustment independent variables ensuring the applicability conditions with a significance level set at $5 \%$.

Variables with $\mathrm{p}$ less than 0.25 in bivariate analysis were used for modeling [9]. The lrtest (likelihood ratio) and AIC allowed the choice of the latter with the step-down method.

Finally, the test of Hosmer-Lemeshow tested the adequacy of the final model [10]. Associations were measured by odds ratios with their confidence intervals.

\subsection{Ethical Considerations}

The consent of the interviewees was previously acquired. Respondents were informed of the objectives and constraints of the study, their rights to refuse to participate in the study or to leave it at any time. Anonymity and confidentiality were respected.

Table 1. Knowledge answers coding.

\begin{tabular}{|c|c|c|}
\hline Knowledge questions & Expected responses & Good knowledge \\
\hline $\begin{array}{l}\text { How does cervical } \\
\text { cancer manifest? }\end{array}$ & $\begin{array}{l}\text { - Vaginal bleeding (between periods, after } \\
\text { sex, in postmenopausal women) } \\
\text { - Serous-bloody vaginal discharge } \\
\text { - Appearance of abdominopelvic pains or } \\
\text { during sexual intercourse } \\
\text { - Increased duration of menstruation }\end{array}$ & $\begin{array}{l}\text { Woman who cited } \\
\text { vaginal bleeding with } \\
\text { two other signs }\end{array}$ \\
\hline $\begin{array}{l}\text { Can cervical cancer be } \\
\text { cured? }\end{array}$ & $\begin{array}{l}\text { - Yes, he can be cured } \\
\text { - Detected early it can be cured } \\
\text { - Tracked late, sometimes it can't be cured }\end{array}$ & $\begin{array}{l}\text { Woman who cited at } \\
\text { least one of the expected } \\
\text { answers }\end{array}$ \\
\hline $\begin{array}{l}\text { How can cervical cancer } \\
\text { be identified early? }\end{array}$ & $\begin{array}{l}\text { - Gynecological examination with visual } \\
\text { inspection } \\
\text { - Smear } \\
\text { - Colposcopy }\end{array}$ & $\begin{array}{l}\text { Woman who cited at } \\
\text { least one of the expected } \\
\text { answers }\end{array}$ \\
\hline $\begin{array}{l}\text { Where can cervical } \\
\text { cancer be screened? }\end{array}$ & $\begin{array}{l}\text { - Health posts } \\
\text { - Health centers } \\
\text { - Hospitals } \\
\text { - Private gynecological clinics and practices }\end{array}$ & $\begin{array}{l}\text { Woman who cited at } \\
\text { least one of the expected } \\
\text { answers }\end{array}$ \\
\hline
\end{tabular}




\section{Results}

A sample of 599 women was surveyed during this study.

The average age of the sample was 44.4 years with a standard deviation of 8.9 and a median of 42 years. The maximum age was 65 years.

The study showed that $46.6 \%$ of respondents were out of school followed by $33.6 \%$ who had a primary level. $64.9 \%$ of women had income-generating activities.

The women surveyed were aware of cervical cancer screening sites (80.6\%) diagnostic methods (74.5\%). The possibility of cure of cancer was known by $28.4 \%$ of women, and one case of cervical cancer was known by $16.2 \%$ of the women surveyed. However, the symptomatology of cervical cancer was less known (18.4\%). A proportion of $19.4 \%$ of women had already been screened for cervical cancer (Table 2).

The practice of screening for cervical cancer was related to the age of the woman $(\mathrm{p}=0.041)$. The women screened had an average age of 45.8 years, the not screened women had 44.0 years.

In bivariate analysis, cervical cancer screening was positively associated with the existence of income-generating activity in women $(p=0.006)$ and increased levels of socio-economic well-being $(\mathrm{p}<0.001)$. This screening was also positively associated with knowledges of a case of cervical cancer in the environment ( $\mathrm{p}<0.001)$, cancer symptoms $(\mathrm{p}<0.001)$, the possibility of cure $(\mathrm{p}<0.001)$, diagnostic methods $(\mathrm{p}<0.001)$ and screening sites $(\mathrm{p}<0.001)$. This screening was not related to schooling and marital status (Table 3 ).

In multivariate analysis, cervical cancer screening was positively related to the possession of income-generating activity $(\mathrm{aOR}=2.39)$.

Compared to not-in-school women, primary education was not statistically associated with screening. However, secondary and higher levels were associated with the practice of this screening with adjusted odds ratios, respectively of 2.46 and 6.22.

Knowledge of a person with cervical cancer and diagnostic methods were positively associated with cervical cancer screening (Table 4).

\section{Discussion}

At the end of this study, the survey concerned 599 women aged 35 to 65 from the district of Mbour. Among women, those who had screened for cervical cancer at the time of the survey represented 19\%. Having an income-generating activity, the level of education, knowing someone who has had cervical cancer and knowing the methods of diagnosing cancer were statistically associated with the practice of cervical cancer uterus screening. The main limitation of this study remains the fact that the data collected were declarative. No evidence of the realization of cervical cancer screening was provided by the women. However, given the absence of taboos on this practice, and the collection that took place under confidentiality conditions make it possible to prejudge the absence of bias related to this fact. 
Table 2. Characteristics of women $(n=599)$.

\begin{tabular}{|c|c|c|}
\hline Parameters & Absolute frequencies (n) & Relative frequencies (\%) \\
\hline \multicolumn{3}{|c|}{ Income-generating activity } \\
\hline Yes & 389 & 64.9 \\
\hline No & 210 & 35.1 \\
\hline \multicolumn{3}{|l|}{ Marital status } \\
\hline Single & 24 & 4.0 \\
\hline Married & 487 & 81.4 \\
\hline Divorced & 44 & 7.3 \\
\hline Widow & 44 & 7.3 \\
\hline \multicolumn{3}{|l|}{ Level of education } \\
\hline Not in school & 279 & 46.6 \\
\hline Primary & 201 & 33.6 \\
\hline Secondary & 100 & 16.7 \\
\hline Higher & 19 & 3.2 \\
\hline \multicolumn{3}{|c|}{ Level of household well-being } \\
\hline Poorer & 73 & 12.2 \\
\hline Poor & 183 & 30.6 \\
\hline Rich & 158 & 26.4 \\
\hline Richer & 185 & 30.9 \\
\hline \multicolumn{3}{|c|}{ Knowledge of a cancer case in the environment } \\
\hline Yes & 97 & 16.2 \\
\hline No & 502 & 83.8 \\
\hline \multicolumn{3}{|c|}{ Knowledge of cancer symptoms } \\
\hline Good & 110 & 18.4 \\
\hline $\mathrm{Bad}$ & 489 & 81.6 \\
\hline \multicolumn{3}{|c|}{ Knowledge of possibility of curred } \\
\hline Yes & 170 & 28.4 \\
\hline No & 429 & 71.6 \\
\hline \multicolumn{3}{|c|}{ Knowledge of a diagnostic method } \\
\hline Yes & 446 & 74.5 \\
\hline No & 153 & 25.5 \\
\hline \multicolumn{3}{|c|}{ Knowledge of screening sites } \\
\hline At least one site cited & 478 & 79.8 \\
\hline No known site & 121 & 20.2 \\
\hline \multicolumn{3}{|c|}{ Cervical cancer screening } \\
\hline Yes & 116 & 19.4 \\
\hline No & 483 & 80.6 \\
\hline
\end{tabular}


Table 3. Factors associated with cervical cancer screening in bivariate analysis $(n=599)$.

\begin{tabular}{|c|c|c|}
\hline Parameters & Cervical cancer screening $\mathrm{n}(\%)$ & p-value \\
\hline \multicolumn{3}{|l|}{ Income-generating activity } \\
\hline Yes & $88(22.6)$ & 0.006 \\
\hline No & $28(13.3)$ & \\
\hline \multicolumn{3}{|l|}{ Marital status } \\
\hline Single & $4(16.7)$ & \\
\hline Married & $93(19.1)$ & 0.922 \\
\hline Divorced & $9(20.5)$ & \\
\hline Widow & $10(22.7)$ & \\
\hline \multicolumn{3}{|l|}{ Level of education } \\
\hline Not in school & $42(15.1)$ & \\
\hline Primary & $46(22.9)$ & 0.097 \\
\hline Secondary & $24(24.0)$ & \\
\hline Higher & $4(21.1)$ & \\
\hline \multicolumn{3}{|c|}{ Level of household well-being } \\
\hline Poorer & $7(9.6)$ & \\
\hline Poor & $21(11.5)$ & $<0.001$ \\
\hline Rich & $36(22.8)$ & \\
\hline Richer & $52(28.1)$ & \\
\hline \multicolumn{3}{|c|}{ Knowledge of a cancer case in the environment } \\
\hline Yes & $36(37.1)$ & $<0.001$ \\
\hline No & $80(15.9)$ & \\
\hline \multicolumn{3}{|c|}{ Knowledge of cancer symptoms } \\
\hline Good & $44(40.0)$ & $<0.001$ \\
\hline $\mathrm{Bad}$ & $72(14.7)$ & \\
\hline \multicolumn{3}{|c|}{ Knowledge of possibility of healing } \\
\hline Yes & $90(52.9)$ & $<0.001$ \\
\hline No & $26(6.1)$ & \\
\hline \multicolumn{3}{|c|}{ Knowledge of a diagnostic method } \\
\hline Yes & $27(6.3)$ & $<0.001$ \\
\hline No & $89(52.4)$ & \\
\hline \multicolumn{3}{|c|}{ Knowledge of screening sites } \\
\hline At least one site cited & $3(2.0)$ & $<0.001$ \\
\hline No known site & $113(25.3)$ & \\
\hline
\end{tabular}


Table 4. Factors associated with cervical cancer screening in multivariate analysis $(\mathrm{n}=$ 599).

\begin{tabular}{|c|c|}
\hline Parameters & $\begin{array}{c}\text { Cervical cancer screening } \\
\text { aOR [IC 95\%] }\end{array}$ \\
\hline Age of woman (in years) & $1.03[0.9-1.06]$ \\
\hline \multicolumn{2}{|l|}{ Income-generating activity } \\
\hline Yes & $2.39[1.4-4.2]$ \\
\hline No & 1 \\
\hline \multicolumn{2}{|l|}{ Level of education } \\
\hline Not in school & 1 \\
\hline Primary & $1.09[0.6-2.0]$ \\
\hline Secondary & $2.46[1.1-5.3]$ \\
\hline Higher & $6.22[1.6-24.3]$ \\
\hline \multicolumn{2}{|l|}{ Level of household well-being } \\
\hline Poorer & 1 \\
\hline Poor & $1.3[0.5-4.0]$ \\
\hline Rich & $0.65[0.2-1.9]$ \\
\hline Richer & $0.8[0.3-2.4]$ \\
\hline \multicolumn{2}{|c|}{ Knowledge of a cancer case in the environment } \\
\hline Yes & $2.40[1.3-4.2]$ \\
\hline No & 1 \\
\hline \multicolumn{2}{|c|}{ Knowledge of cancer symptoms } \\
\hline Good & $1.5[0.8-2.7]$ \\
\hline Bad & 1 \\
\hline \multicolumn{2}{|c|}{ Knowledge of possibility of cured } \\
\hline Yes & $1.2[0.6-1.2]$ \\
\hline No & 1 \\
\hline \multicolumn{2}{|c|}{ Knowledge of a diagnostic method } \\
\hline Yes & $20[11.1-33.3]$ \\
\hline No & 1 \\
\hline \multicolumn{2}{|l|}{ Knowledge of screening sites } \\
\hline At least one site cited & $2.5[0.7-10.0]$ \\
\hline No known site & 1 \\
\hline
\end{tabular}

The practice of screening for cervical cancer found in the Mbour district in the study remained high $(19.4 \%)$ compared to that national during the decade 1980-1990 which was estimated at $16.2 \%$ [11] and that of $12 \%$ found at national level [6].

The study showed that cervical cancer screening is not linked to marital status. However, the proportion of women who used cervical cancer screening was 
higher among married women (80\%) than among unmarried women. This result agrees with those of Tieba [12] who found that $25.0 \%$ of married women were screened for cervical cancer against $19.4 \%$ in unmarried women.

Positive relationships exist between seeking care and the woman's profession. In fact, women exercising an income-generating activity (76\%) were more likely to be screened because of their power to better support the expenses generated by their state of health [12]. Indeed, the lack of means often constitutes a brake on the use of health services and screening in particular, this because of the costs linked to the practice of screening: price of consultation, price of test, price of transport to get to the screening site [13].

According to Rondet [14] women's socio-economic characteristics, having a low level of education, having a low-income level, having incomplete health insurance quality, are characteristics associated with delay or lack of participation in screenings for gynecological cancers. Our study also showed that increase in education was statistically associated with cervical screening. Indeed, compared to not-in-school women, primary education was not statistically associated with screening. However, secondary and higher levels were associated with the practice of this screening with adjusted odds ratios, respectively of 2.46 and 6.22 . Similar results had been obtained by Tieba [12].

This relationship could be explained by the fact that women's lack of education would be a hindrance to the apprehension of health problems and the search for adequate solutions, by limiting the use of prevention services. On the other side the instruction of the woman allows her to become aware of the outside world, to assert her rights, to have self-confidence, and to be able to influence decisions affecting herself.

The study showed that knowledge of symptoms is a key element in adhering to screening for cervical cancer. This result agrees with that of Mahdaoui E [15] where the main symptom of cervical cancer known by women is metrorrhagia (67\%).

Knowledge of a case of cervical cancer was associated with the practice of screening for it by women. A similar result is established by Tieba M. [12]. It emerges from this study that $40 \%$ of women who had declared having had parents who were victims of this disease had recourse to screening against $12.3 \%$ for the others. Indeed, the perception of risk is higher at this level $(\mathrm{p}<0.001)$. The presence of a case of cervical cancer is therefore a strong message of communication to get women in the environment to carry out the screening, probably due to a better understanding of the reality of the cancer and the risk involved.

Knowledge of diagnostic methods has also been a factor associated with cervical cancer screening. However, this relationship is not deterministic. Indeed, a good knowledge of diagnostic methods could just result from the screening itself.

In general, the level of knowledge of cancer and screening is an important dimension to be considered as being a determinant of the use of screening since it 
constitutes a basic data for understanding the perception of cervical uterus cancer and screening by women [12].

\section{Conclusions}

Cervical cancer is a serious infectious disease, the incidence of which is still high, especially in developing countries. It is a disease whose evolution is slow which makes it possible to stop the evolution if the diagnosis is made early. However, at the level of the Mbour health district, the screening rate remains low (19\%) due to the lack of knowledge of women on this pathology in relation to the low level of education or the socioeconomic level.

To improve this poor practice of cervical cancer screening, countries must make this pathology a priority by implementing a relevant program that will target the empowerment of women through an improvement in their educational and economic levels.

\section{Conflicts of Interest}

The authors declare no conflicts of interest regarding the publication of this paper.

\section{References}

[1] Haute autorité de la santé (2010) Etats des lieux et recommandations pour le dépistage du cancer du col de l'utérus en France. HAS, 17-18.

[2] Organisation mondiale de la santé (2007) Lutte contre le cancer du col de l'utérus. Guide des pratiques essentielles. 217 p.

[3] Direction de la recherche des études de l'évaluation et des statistiques (2009) La santé des femmes en France. La documentation française

[4] Sankaranarayan, R. (2001) Programmes efficaces de dépistage du cancer du col dans les pays en voie de développement à revenu faible ou moyen. Bulletin of World Health Organisation, 79, 954-962.

[5] Réseau Régional d'Afrique de l'Organisation mondiale de la Santé (2010) Comité régional d'Afrique. Soixantième session Point 7.4 de l'ordre du jour provisoire; Aout-Septembre 2010 ; Malabo, Guinée-Equatoriale.

[6] Ministère de la santé et de l'action sociale (2016) Enquête nationale STEPS 2015. MSAS.

[7] Andersen, R.M. (1995) Revisiting the Behavioral Model and Access to Medical Care : Does It Matter? Journal of Health and Social Behavior, 36, 1-10. https://doi.org/10.2307/2137284

[8] R Core Team (2015) A Language and Environment for Statistical Computing. R Foundation for Statistical Computing, Vienna, Austria. http://www.r-project.org/

[9] Collet, D. (2003) Modeling Binary Data. CRC, London, 387 p.

[10] Hosmer, D.W. and Lemeshow, S. (1989) Applied Logistic Regression. John Wiley, New York, 307 p.

[11] Afoutou, J.-M. (2008) Une décennie de dépistage colpocytologique au CHU de Dakar. Journal Scientifique, 8, 1-16.

[12] Tieba, M.T. (2012) Étude des déterminants du recours au dépistage du cancer du col 
de l'utérus dans le district centre de Dakar. Mémoire Diplôme d'Etudes Supérieures Spécialisées en Économie de la santé. CESAG, 87 p.

[13] Romaine, R. (2002) Étude pilote de dépistage du cancer du col de l'utérus dans une région rurale camerounaise. Archive ouverte-Unige.

[14] Rondet, C. (2016) Déterminants socio-territoriaux de l'absence ou du retard de participation aux dépistages des cancers féminins. Impact de l'origine migratoire et du lien social. Une étude en population générale à partir des données de la cohorte SIRS. Sante publique et épidémiologie. Université Pierre et Marie Curie-Paris VI, 98 p.

[15] Mahdaoui, E. (2012) Facteurs d'adhésion au dépistage du cancer du sein et du col de l'utérus aux préfectures médicales de Rabat et SkhimatTémara. Mémoire INAS. Master administration sanitaire et santé publique. 